\title{
Diagnosing human asymptomatic visceral leishmaniasis in an urban area of the State of Minas Gerais, using serological and molecular biology techniques
}

\author{
Diagnóstico da leishmaniose visceral humana assintomática \\ em uma área urbana do Estado de Minas Gerais, usando \\ métodos sorológicos e biologia molecular
}

\author{
Elizabeth Castro Moreno', Maria Norma Melo², José Roberto Lambertucci³, \\ José Carlos Serufo ${ }^{3}$, Antero S.R. Andrade ${ }^{4}$, Carlos Maurício F. Antunes ${ }^{5}$ \\ Odair Genaro $\dagger$ and Mariângela Carneiro ${ }^{2}$
}

\begin{abstract}
A population-based cross-sectional study was set up in Sabará country, Southeastern Brazil, to identify asymptomatic human visceral leishmaniasis in an urban area of low disease prevalence. Blood was collected on filter paper ( $n=1,604$ inhabitants) and examined by indirect immunofluorescent test, enzyme-linked immunosorbent assay and immunochromatographic strip test. The prevalence rates of infection ranged from 2.4 to $5.6 \%$ depending on the test used. One year later, venous blood was collected in a subset of 226 participants (102 seropositive and 124 seronegative). The tests performed were IFAT, ELISA, rk39ELISA, polymerase chain reaction and hybridization with Leishmania donovani complex probe. No clinical signs or symptoms of leishmaniasis were observed. Using hybridization as a reference test, the sensitivity and specificity of serology were respectively: 24.8 and $71 \%$ (ELISA); 26.3 and 76.3\% (rk-39); 30.1 and 63.4\% (IFAT). Due to disagreements, different criteria were tested to define the infection and hybridization should be considered in epidemiological studies.
\end{abstract}

Key-words: Asymptomatic visceral leishmaniasis. Leishmania chagasi. Prevalence rate. Diagnostic. Hybridization.

\section{RESUM0}

Um estudo seccional de base populacional foi desenvolvido no município de Sabará, região sudeste do Brasil, para identificar a leishmaniose visceral humana assintomática em uma área urbana de baixa prevalência da doença. Foi coletado sangue em papel filtro ( $n=1.604$ moradores), sendo examinados pela reação de imunofluoresência indireta, ensaio imunoenzimático e teste imunocromatográfico (strip test). As taxas de prevalência da infecção variaram de 2,4 a 5,6\%, dependendo do teste utilizado. Um ano depois foi coletado sangue venoso de um subgrupo de 226 participantes (102 soropositivos e 124 soronegativos). Os testes realizados foram IFAT, ELISA, rk39-ELISA, reação em cadeia da polimerase e hibridização com sonda específica para o complexo Leishmania donovani. Não foi observado nenhum sinal clínico ou sintoma de leishmaniose. Usando a hibridização como teste de referência, a sensibilidade e especificidade dos testes sorológicos foram, respectivamente: 24.8 e 71\% (ELISA); 26,3 e 76,3\% (rk39-ELISA); 30,1 e 63,4\% (IFAT). Devido a discordâncias, diferentes critérios foram testados para definir a presença da infecção e a hibridização deveria ser considerada em estudos epidemiológicos.

Palavras-chaves: Leishmaniose visceral assintomática. Leishmania chagasi. Taxa de prevalência. Diagnóstico. Hibridização .

1. Fundação Nacional de Saúde, Belo Horizonte, MG. 2. Departamento de Parasitologia do Instituto de Ciências Biológicas da Universidade Federal de Minas Gerais, Belo Horizonte, MG. 3. Departamento de Clínica Médica da Faculdade de Medicina da Universidade Federal de Minas Gerais, Belo Horizonte, MG. 4. Comissão Nacional de Energia Nuclear do Centro de Desenvolvimento da Tecnologia Nuclear, Belo Horizonte, MG. 5. Santa Casa de Belo Horizonte, Belo Horizonte, MG.† In memoriam. Partially supported by Ministry of Health, Brazil, Project Vigisus, Conselho Nacional de Desenvolvimento Científico e Tecnológico, Fundação de Amparo a Pesquisa de Minas Gerais and UNCEF/UNDP/World Bank/WHO Special Programme for Research and Training in Tropical Diseases (TDR).

Address to: Dra Mariângela Carneiro. Deptํํㅁe Parasitologia/ICB/UFMG. Av. Antônio Carlos 6627, Caixa Postal 486, 31279-901 Belo Horizonte, MG. Brasil.

Tel: 5531 3499-2839; Fax: 5531 3499-2860

e-mail: mcarneir@icb.ufmg.br

Recebido para publicação em 2/12/2005

Aceito em 10/8/2006 
Visceral leishmaniasis (VL) in Latin America is caused by Leishmania $(L)$ chagasi, a protozoan belonging to the Leishmania donovani complex, mainly transmitted by a sand fly, Lutzomyia longipalpis. Dogs are considered as the principal parasite reservoir, playing a central role in the transmission cycle to humans. $\mathrm{VL}$ is endemic in the rural areas of most Northeastern Brazilian states. It is nowadays considered as a reemerging infection due to its rapid expansion to non-endemic areas. During the last decade, VL clinical cases and deaths have been reported in increasing numbers, in large cities located in different Brazilian states ${ }^{31}{ }^{34}$.

The occurrence of individuals harboring asymptomatic or oligosymptomatic L. chagasi infections in Brazil without progression to the disease has been reported in investigations conducted in Northeastern Brazil ${ }^{34} 6111314161718$. One of the most important drawbacks in these studies is the difficulty of diagnosing patients in this phase, because of the low level of antibodies and reduced parasite numbers ${ }^{25} 27$.

Population-based studies in urban areas are scarce and, when carried out, use immunological tests, mainly the enzyme-linked immunosorbent assay (ELISA), indirect immunofluorescent antibody test (IFAT) ; tests that present high sensitivity for disease, but do not discriminate between past and current infection; and the skin-test, positive in asymptomatic infection ${ }^{6}$ and in patients with a past history of visceral leishmaniasis. Specific antigens from the L. donovani complex have been used in ELSA and in an immunochromatographic strip test for the identification of active, subclinical and asymptomatic VL in specific population groups ${ }^{24}{ }^{23}$. Molecular biology techniques, such as polymerase chain reaction (PCR) alone or in combination with hybridization have been used, especially in blood, to confirm the VL diagnosis in suspect cases, due to their sensitivity (ranging from 75 to 98\%) and specificity (ranging of 97 to 100\%) in identifying the infection in individuals with low levels of parasites and antibodies in the absence of symptoms ${ }^{1212} 2627$.

Regarding VL expansion and urbanization in Brazil, more precise estimates of asymptomatic L. chagasi infection occurrence in a given population are necessary in order to understand the extension of the transmission. The objective of this study was the identification of asymptomatic VL cases in a population resident in an urban area, assaying different immunological and molecular biology diagnostic techniques.

\section{PATIENTS AND METHODS}

Study design and population. This study was conducted to evaluate asymptomatic $L$. chagasi infection in an urban area of General Carneiro district with a population of 19,500 inhabitants, situated in Sabará County, of the Metropolitan Region of Belo Horizonte, capital of the Minas Gerais State, Brazil. For the last 15 years serological canine surveys conducted routinely by the local Public Health Services have revealed prevalence rates ranging from 5 to $10 \%$. Sporadic human cases and deaths have been reported. From 1989 to 2004, 13 cases of human VL have been reported from General Carneiro, with the occurrence of one fatality. Additionally, cutaneous leishmaniasis caused by L. (V.) braziliensis, has been reported by the health services.

A cross-sectional study was conducted in 1998, using serological tests in blood samples collected in filter paper. The sample size $(\mathrm{n}=1,328)$ was calculated based on the following parameters: 1) an estimated human infection prevalence rate of $3.1 \%$, based on a study conducted in the State of Bahia ; 2) precision of the estimate ranging from $2.2 \%$ to $4 \%$; 3) $\mathrm{a}$ error $=0.05$ and 4) population in the study area $=19,500$ inhabitants. For operational reasons, households were used as sampling units. A simple random sample of city blocks was selected proportionally to the existent blocks, and within each selected block, a random sample of households was drawn, proportionally to the number of existent houses. All inhabitants of the selected houses were eligible and were enrolled in the cross- sectional study. A total of 440 households were visited and 1,604 inhabitants were selected ( $8.2 \%$ of the population of General Carneiro) .

The mean age of the 1,604 participants was 26.8 ( \pm 18.6 ) years, the median age was 23 years ( 25 and $75 \%$ inter-quartile range were 13 and 38, respectively); $51.7 \%$ were female; $69.7 \%$ had received only elementary school education and $9.8 \%$ had never gone to school. The mean period of residence in this area was 15 ( \pm 11.2$)$ years.

After 12 months, a subset of 128 participants, who proved positive in serological tests, was enrolled to investigate the course of the infection. A random subset of 128 negative participants was also included as a comparison group. The participants were clinically examined for signs and symptoms of VL in an outpatients clinic of the General Carneiro Public Health Services, interviewed, and a sample of blood was collected and tested for infection using serological and molecular methods.

The study was approved by the Ethical Review Board of the Federal University of Minas Gerais. All participants or their legal guardians, in the case of minors, were required to sign an Informed Consent Form before data collection. Medical attendance and treatment, if necessary, were guaranteed for all participants.

Data collection. In the cross-sectional study, blood samples were collected by finger prick onto filter paper ( Klabin $\mathrm{nr} 25$, Brazil) dried and stored at $4^{\circ} \mathrm{C}$ until testing. Spots of $5 \mathrm{~mm}$ in diameter were eluted in phosphate-buffered saline (PBS) and examined by IFAT; same size spots were eluted in casein-PBS for testing by ELISA using crude antigen and strip test. In the second evaluation carried out after 12 months, blood was collected in a vacuum tube without anticoagulant; the sera were stored at $-20^{\circ} \mathrm{C}$ and later tested by ELISA using both crude and rk39 recombinant antigens and by IFAT. A second vacuum tube with EDTA was used to collect blood for peripheral mononuclear cells ( PBMC), later used for DNA extraction.

Laboratory tests. Indirect immunofluorescent test: the IFAT was performed according to established methodology30; promastigotes of Leishmania (L). amazonensis (MHOM/BR/1960/BH6), 
routinely used in the diagnosis of Leishmania, grown to stationary phase in LIT ( Liver Infusion Tryptose) medium were used. The samples were considered positive when fluorescence was observed at 1:40 dilution.

Enzyme-linked immunosorbent assay: crude antigen was obtained from the same $L$. amazonensis strain used for IFAT, according to established methods ${ }^{35}$; rk39 recombinant antigen ( specific to the L. donovani complex) was used, as previously described ${ }^{5}$. Antibodies were detected with goat conjugated peroxidase-labeled anti-human IgG ( Sigma Co, US). Reactions were read at $492 \mathrm{~nm}$. The cut-off values established for each reaction (ELISA in filter paper and serum, and rk39-ELISA in serum) were the mean absorbancy value + 2 standard deviations from 20 known negative sera at a 1:80 dilution).

Immunochromatographic strip test: this test used the rk39 antigen and was conducted as previously described, using blood eluted from filter paper ${ }^{33}$. Three trained observers read the strips independently; the test was only considered to be positive when the results obtained by all three readers were in agreement.

Anti-Trypanosoma cruzi antibodies: due to crossreactivity in serological tests, serum samples were also assayed for T. cruzi antibodies using indirect hemagglutination (Chagas Kit -FUNED-SES/MG, Brazil) and IFAT (Chagas Kit BioManguinhos - FIOCRUZ, Brazil).

DNA isolation: PBMC were isolated from $8 \mathrm{ml}$ peripheral blood collected in EDTA-coated tube after centrifugation with Ficoll-Paque (Pharmacia, Uppsala, Sweden). DNA was extracted by phenol/chloroform/isoamyl alcohol and ethanol precipitated, resuspended in $30 \mu \mathrm{ll}$ low TE buffer and stored at $4^{\circ} \mathrm{C}$.

PCR amplification: a pair of primers were used to amplify a fragment of $120 \mathrm{bp}$ of the conserved region of Leishmania kDNA minicircle $[5(\mathrm{G} / \mathrm{C})(\mathrm{G} / \mathrm{C})(\mathrm{C} / \mathrm{G}) \mathrm{CC}(\mathrm{A} / \mathrm{C}) \mathrm{CTAT}(\mathrm{A} / \mathrm{T})$ TTACACCAACCCC - $3^{\prime}$ and 5'-GGGGAGGGGCGTTCTGCGAA $\left.3^{\prime}\right]^{15}{ }^{32}$. For all reactions $100 \mathrm{ng}$ of each primer, $2 \mathrm{mM}$ dNTP mixture, $1.5 \mathrm{mM} \mathrm{MgCl}_{2} 2.5 \mathrm{U}$ Taq DNA polymerase (Amplitaq gold-Perkin Elmer) were used in a total reaction volume of $25 \mathrm{ml}$, including $1 \mathrm{ml}$ of sample of DNA. The reactions were cycled in a thermal cycler ( PTC-100, MJ Research, Inc). The following conditions were used: an initial denaturation step at $95^{\circ} \mathrm{C}$ for $4 \mathrm{~min}$, followed by 30 cycles at $94^{\circ}$ for $30 \mathrm{sec}, 50^{\circ}$ for $30 \mathrm{sec}$ for annealing, $72^{\circ}$ for $30 \mathrm{sec}$ for extension. In the final cycle the extension step was extended to 10 minutes. Positive and negative controls were used in all reactions performed. A 100-bp DNA ladder (Gibco BRL®) was used as a marker. Samples were regarded as positive when revealing bands of $120 \mathrm{bp}$. Negatives samples were tested for the human ß-globin gene to confirm that DNA was not degraded and that inhibition in PCR exams had not occurred. Procedures to avoid carryover contamination from previously amplified DNA were used routinely ${ }^{19}$.

PCR product analyses and DNA hybridization: the reaction products were visualized in $5 \%$ polyacrylamide gel electrophoresis stained with silver ${ }^{29}$. The amplified DNA was denatured and applied to nylon membranes ( Biodyne A, Gibco
BRL $®$ ) using a bio-dot apparatus (Hybri-dot manifold-BRL $®$ ). Probes composed of cloned minicircles from $L$. chagasi were radiolabeled with ${ }^{32} \mathrm{P}$ - [a] dCTP using the Random Primer DNA Labeling System ( Gibco BRL) ${ }^{32}$. Hybridization conditions were as previously described ${ }^{1}$.

Positive and negative controls: true negative and positive controls; confirmed by clinical, parasitological, serological and molecular tests; were included in all diagnostic tests performed.

Reproducibility: ten percent of blood samples collected on filter paper and DNA samples were randomly selected and marked for retesting; each duplicate received a different number from the original sample.

Nutritional status: malnutrition was determined by analyzing the children's weight and height for age according to the population pattern of the Reference National Center Health Statistics, using EPI-NUT/EPI-INFO (version 6.04d). Participants over ten years were evaluated using the ratio of weight by square height.

Statistical analysis: the agreement between qualitative tests was estimated by the kappa statistic ${ }^{28}$; quantitative results were compared by Pearson's correlation ( $r$ ), using log titer +1 (IFAT) and absorbances (ELISA).

\section{RESULTS}

Cross-sectional study. The description of the population studied was realized elsewhere ${ }^{22}$.

Table 1 shows the estimated prevalence rates by each serological test performed in eluates. Only eleven (6.4\%) samples were simultaneously positive in two techniques. If we consider as probably infected those samples which showed a positive result in at least one test performed, the estimated prevalence rate was $10.7 \%$ (171/1604).

Table 1 - Reactivity of the samples collected in filter paper in a serological survey $(n=1,604)$ to identify the seroprevalence of infection by Leishmania in General Carneiro-Sabará/MG, 1998.

\begin{tabular}{lcc}
\hline & \multicolumn{2}{c}{ Positive samples } \\
\cline { 2 - 3 } Serological Tests & number & prevalence IC $95 \%^{-}$ \\
\hline IFAT & 38 & $2.4(1.7-3.3)$ \\
ELSSA & 54 & $3.4(2.6-4.4)$ \\
Strip test & 90 & $5.6(4.5-6.9)$ \\
Positive in at least one test & $171^{c}$ & $10.7(9.2-12.2)$ \\
\hline
\end{tabular}

aPrevalence $=$ positive test $1604 .{ }^{b}$ Crude antigen. ${ }^{c} 11$ samples were positive in two tests simultaneously: IFAT and ELISA $=8$; Strip test and ELISA or IFAT $=3$

The evaluation of test reproducibility ( duplicates) showed good agreement for IFAT (kappa 0.74, 95\% CI 0.40-1.0), regular for ELISA (kappa 0.53, 95\% CI 0.18-0.89) and poor agreement for the strip test (kappa 0.14, 95\% CI -0.11-0.40). Pearsons' correlation for ELISA absorbency and IFAT titers for duplicates were $r=0.63$ and $r=0.76$, respectively.

Follow up phase. Two hundred and fifty-six participants were invited to return for reevaluation 12 months after the 
cross-sectional study: One hundred and eight positive participants included all the participants that were positive in ELSA or IFAT $(n=84)$ and $50 \%(n=44)$ of those positive in strip tests ( randomly chosen among those positive in this test; a decision based on the poor reproducibility of the test). A subset of 128 negative participants was randomly selected among those negative in all tests performed.

Thirty participants were lost during the follow up ( 26 among the positive group and 4 among the negative) due to refusals, death, relocation or insufficient biological material. The final sample evaluated comprised 226 participants: 102 positive and 124 negative. Comparison of the demographic characteristics, such as age, gender and period of residence in General Carneiro, revealed no differences $(p>0.05)$ between the positive subjected included and those not included in this phase. The negative participants showed a similar result $(p>0.05)$ among the negative population when the same variables were compared. The characteristics of the 226 participants are shown in Table 2. This group constitutes a cohort and the data showed refer to this first evaluation.

Table 3 shows the results of serological tests of the sera of the 226 participants examined. Positive in sera include both positive and negative in the cross-sectional study. It is worth noting that 130 (57.5\%) were positive in atleast one testand 49 (37.7\%) were simultaneously positive in two or three techniques; 96 (42.5\%) were considered negative in all the tests performed.

Table 2 - Distribution of some demographical and social characteristics of the 226 participants from General Carneiro, Sabará/MG evaluated by serological and molecular techniques to diagnose asymptomatic visceral leishmaniasis

\begin{tabular}{|c|c|c|}
\hline Variables & Number & Percentage \\
\hline \multicolumn{3}{|l|}{ Gender } \\
\hline female & 119 & 52.7 \\
\hline male & 107 & 47.3 \\
\hline \multicolumn{3}{|l|}{ Race } \\
\hline white & 55 & 24.3 \\
\hline black & 43 & 19.0 \\
\hline mullato & 128 & 56.6 \\
\hline \multicolumn{3}{|l|}{ Age groups } \\
\hline$>10$ years old & 160 & 70.8 \\
\hline 1 - 10 years old & 66 & 29.2 \\
\hline \multicolumn{3}{|l|}{ Education ${ }^{1}$} \\
\hline college and high school & 21 & 12.0 \\
\hline elementary school & 135 & 77.1 \\
\hline no schooling & 19 & 10.9 \\
\hline \multicolumn{3}{|l|}{ Income ( minimum wage) } \\
\hline $0-3$ & 102 & 45.1 \\
\hline$>3-15$ & 124 & 54.9 \\
\hline \multicolumn{3}{|c|}{ Natural of metropolitan region² } \\
\hline yes & 146 & 68.5 \\
\hline no & 67 & 29.6 \\
\hline \multicolumn{3}{|l|}{ Period of residence } \\
\hline $1-5$ years & 55 & 24.3 \\
\hline$>5$ years & 171 & 75.7 \\
\hline mean \pm SD & \multicolumn{2}{|c|}{$16.0 \pm 11.3$} \\
\hline median (IQR) & \multicolumn{2}{|c|}{$13.5(7 / 24)$} \\
\hline
\end{tabular}

IQR1/Q3= 25\% and 75\% inter quartil range

${ }^{1}$ only for more than 7 years old; $n=175 .{ }^{2}$ data for refusals, not known and not done are notshown
Table 3 - Reactivity of the 226 sera for Leishmania infection in follow-up phase, General Carneiro-Sabará/MG, 1999.

\begin{tabular}{lcc}
\hline & \multicolumn{2}{c}{ Positive samples } \\
\cline { 2 - 3 } Serological Tests & $n^{0}$ & proportion $^{\text {a }}(\%)$ \\
\hline IFAT & 74 & 32.7 \\
ELISA & 60 & 26.5 \\
rk39-ELSA & 57 & 25.2 \\
positive in at least one test & $130^{\text {b }}$ & 57.5 \\
\hline
\end{tabular}

a Proportion $=$ positive test $/ 226 .{ }^{\mathrm{b}} 49$ samples among of 130 samples were positive in two or three tests simultaneously

Molecular test results. Among the 226 samples examined, 133 were positive in hybridization with a specific probe for the $L$. donovani complex.

Figure 1 shows a representative electrophoresis gel of PCR products and dot-blot hybridization with specific probes. The PCR and hybridization negative samples were analyzed by PCR with specific primers for the human $ß$-globin gene; the tests confirmed the presence of human DNA in all samples. In addition, the evaluation of test reproducibility, 23 blind duplicates, revealed that PCR showed good agreement ( kappa 0.89, 95\% CI 0.67-1.0).

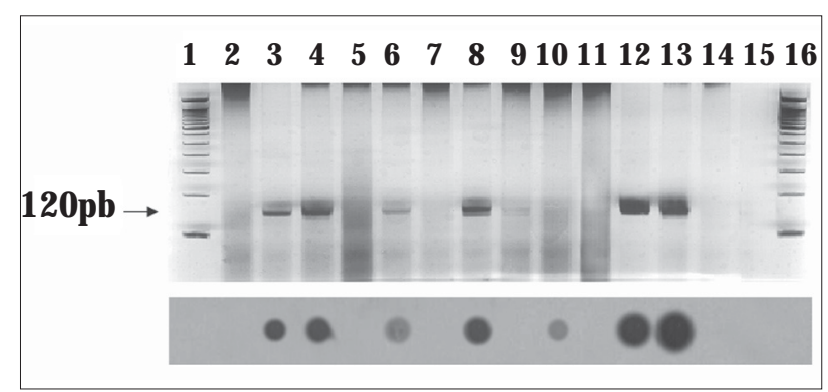

Figure 1 - Representative polyacrylamide gel showing an amplification product of 120bp from $\mathrm{kDNA}$ minicircles of Leishmania in blood samples from asymptomatic individuals and dot blot hybridization of the same $P C R$ products performed with $\mathrm{L}$. donovani complex specific $\mathrm{kDNA}$ probe. Lanes $3,4,6,8$ show samples that were positive in the PCR and hybridization assays; sample in lane 10 was positive for hybridization although the amplified products are not visible in the electrophoresis gel. Lane 9 shows a weakly PCR positive sample but negative for hybridization. Lanes 1and 16: molecular size markers (100bp ladder). Positive controls: lane 12 amplification product from the blood of a patient with kala-zar and lane 13 - DNA of cultured L. chagasi. Negative controls: lane 14 - non-infected individual and lane 15 - no DNA in the PCR reaction mixture.

Comparison among hybridization and serological methods. The comparison of the results obtained in hybridization and serologic tests is shown in Table 4. Among the 133 positive samples in hybridization, 74 (55.6\%) were positive in at least one serological test and among the 93 negative in hybridization, 56 $(60.2 \%)$ were positive in at least one serological test. Therefore, if the hybridization is considered a reference diagnostic test for asymptomatic VL, the sensitivity estimate of serological techniques ranged from 24.8 to $30.1 \%$ and specificity ranged from 63.4 to $76.3 \%$.

Cross-reaction with Chagas' disease. Eight participants were identified as showing positive tests ( Indirect Hemagglutination and IFAT) indicating possible T. cruzi infection; among these four were also reported as having Chagas' disease and six were positive in the hybridization or rk39-ELISA, suggesting a T. cruzi/L. chagasi coinfection. 
Table 4 - Estimates of sensitivity and specificity of the diagnostic tests in identifying $\mathrm{L}$, chagasi infection using the DNA hybridization as the reference test. General Carneiro -Sabará/MG, 1999.

\begin{tabular}{lcccc}
\hline & $\begin{array}{c}\text { Positive in } \\
\text { serology and } \\
\text { hybridization }\end{array}$ & $\begin{array}{c}\text { Sensitivity } \\
(\text { IC 95\%) })^{1}\end{array}$ & $\begin{array}{c}\text { Negative in } \\
\text { serology and } \\
\text { hybridization }\end{array}$ & $\begin{array}{c}\text { Specificity } \\
(\text { IC 95\%) })^{2}\end{array}$ \\
Serology & 40 & $30.1(22.4-38.6)$ & 59 & $63.4(52.8-73.2)$ \\
IFAT & 33 & $24.8(17.7-33.0)$ & 66 & $71.0(60.6-79.9)$ \\
ELSSA & 35 & $26.3(19.1-34.7)$ & 71 & $76.3(66.4-84.5)$ \\
rk39-ELISA & 74 & $55.6(46.8-64.3)^{3}$ & 374 & 39.8 (29.8-50.5) \\
Serological tests & 74 &
\end{tabular}

Clinical examination. Signs and symptoms related to visceral leishmaniasis were neither observed nor reported during clinical examination. Only six participants (one child) showed low hematocrit $(<30 \%)$, but with no significant differences in all other clinical criteria used to define infection; (fever, hepatomegaly and/or splenomegaly and weight loss).

Malnutrition. Eight malnourished children were identified, though none of them presented progression to clinical disease. Two were positive in hybridization and four of them were positive only in serological tests.

Criteria for $L$. chagasi infection. Due to the disagreements found in the tests to identify asymptomatic infection using different diagnostic methods and the fact that which subjects were in fact infected remains undefined, different criteria were proposed to define $L$. chagasi infection. Criterion 1 , greater specificity: include only participants that were positive in the crude antigen test and the specific antigen test and were confirmed by hybridization for L chagasi; 17 (7.5\%) participants fulfilled this criterion. Criterion 2, parasite presence: include all hybridization positive participants; 133 (58.8\%) individuals were identified. Criterion 3, positive serology and hybridization: include all participants with a positive hybridization and presenting, at least, one positive serological test (crude or specific antigen); 74 (32.7\%) participants were considered as infected by L. chagasi.

\section{DISCUSSION}

Herein, the presence of asymptomatic infection by L. chagasi in an urban area of Southeast Brazil was shown. The prevalence rates of $L$. chagasi infection estimated in a cross-sectional study, by serological methods, ranged from $2.4 \%$ (IFAT) to $5.6 \%$ ( strip test), depending on the serological test used. When considering those samples that gave positive results in at least one of the tests performed, the estimated prevalence rate of infection was 10.7\% (171/1604).

The lack of concordance among the serological tests was a limitation of the present investigation. The discordance among the serological tests can not be explained by errors in conducting the tests, because the evaluation of test reproducibility revealed a good agreement for IFAT, and regular for ELSA; only the strip test revealed poor concordance in the duplicates. The correlations of absorbances (ELISA) or titers (IFAT) in duplicates also were good. Therefore, it can be concluded that serological methods are not appropriate for diagnosing asymptomatic infection in areas of low disease prevalence and occurrence of cutaneous leishmaniasis.

The DNA hybridization technique identified a greater number of positive participants when compared to the serological tests performed. Assuming DNA hybridization as the reference test for identifying individuals with active $L$. chagasi infection, the participants who showed positive serology and negative hybridization results can be considered as false-positives or selfcured of their infection. The positive serology in self-cured subjects could be a consequence of a gradual and slow decrease in titers, as demonstrated in other infections ${ }^{8}$ The serological tests were able to identify the presence of infection in 30.1, 24.8 and $26.3 \%$ of those with positive hybridization (IFAT, ELISA and rk39-ELISA, respectively. Therefore, when the hybridization is considered the reference test, serology (positive for at least one serological test) was able to identify $55.6 \%$ (74/133) of the individuals who were truly infected. Furthermore, serology was able to identify 39.8\% (37/93) of the individuals who were truly negative; specificity of $63.4,71.0$ and $76.3 \%$, for IFAT, ELSA and rk39-ELSA, respectively.

The greatestchallenge of this investigation was to understand the disagreement among the diagnostic methods used to identify asymptomatic $L$. chagasi infection. The different antigens used to perform the tests may explain, in part, the low concordance and correlation among serological tests. The antigen rk39 presents high sensitivity and specificity for the $L$. donovani complex and has been associated with active disease ${ }^{2}$. In the present study, among those positive in hybridization, rk39 showed high specificity $(71 / 93=76.3 \%)$, but low sensitivity for asymptomatic individuals ( $35 / 133=26.3 \%)$. It is also known that ELISA with crude antigen and IFAT present some limitations, such as cross-reacting with other parasitic infections ( eg T. cruzi and other leishmaniasis) or the detection of past infection ${ }^{26}$. Therefore, the use of only one serologic test may not reflect the true prevalence of an infection in a population at risk, leading to misclassification bias in epidemiological studies.

The differentalgorithms proposed to identify infection present specific advantages and limitations. Criterion 1 is more rigorous in defining the infection; however, some true positives could have been excluded because the definition requires positive results in molecular and serological tests with crude and specific antigens. Sera from infected patients may show distinctive recognition of crude and specific antigens and patients with asymptomatic or self-healing infections may present low or undetectable levels of anti-k39 antibodies ${ }^{2}$. Criterion 2 suggests the presence of circulating parasites in the blood, including individuals that were positive in hybridization, independent of the serological results. In criterion 3 some positives were probably excluded because the algorithm is dependent on a serological test and, as mentioned elsewhere, asymptomatic individuals present low levels of antibodies and minute amounts of circulating parasites when compared to symptomatic patients $^{26}$. Thus, the performance of the serological tests 
should be interpreted differently in epidemiological studies devised to identify asymptomatic infection in a population and in studies conducted to diagnose clinical cases or to confirm suspected cases. Moreover, negative hybridization may be due to the amount of blood used, which could have been insufficient to permit the extraction of parasite $\mathrm{DNA}^{23}$.

The lack of a gold standard technique to confirm an active L. chagasi infection in asymptomatic individuals is an important drawback in population studies. The use of invasive procedures to detect the parasite ( spleen, bone marrow, lymph node aspirates) it is not justified for ethical reasons when the patient does not show any symptoms of the disease, which was the case in the present study. Blood culture is not the method of choice to prove the presence of the parasite due to the low sensitivity when assayed in asymptomatic carriers ${ }^{27}$. Although the molecular methods are not easily available for routine testing, DNA hybridization should be preferred in the identification of asymptomatic infection. The hybridization is more specific than serological tests in identifying active infection and can be used to discriminate false positives and false negatives. However, although it is high sensitivity, hybridization can not identify $100 \%$ of the true positive, since parasite presence may be intermittent in peripheral blood ${ }^{20}$.

Other important finding of this study is the absence of clinical disease. The occurrence of asymptomatic and subclinical illness with nonspecific symptoms has been reported in investigations conducted in Northeastern Brazil. However, in these areas clinical cases have been found and the ratio of infected/diseased persons ranged from 6.5:1 to $28: 1^{3616}$. In the area studied, a possible explanation for the absence of the disease would be the low level of malnutrition in the population studied, an important prognostic factor for disease progression ${ }^{4}$. In this investigation, only eight malnourished children were identified and none developed clinical signs or symptoms of VL. Similar results were obtained in cohort studies carried out with children in northeastern Brazil, where asymptomatic and subclinical cases also did not progress to the acute form of $\mathrm{VL}^{61718}$. If $L$. chagasi infection does not progress to visceral leishmaniasis within the first or second year after infection, it is unlikely to do so in otherwise healthy individuals ${ }^{18}$. It is becoming clear that asymptomatic infections should be considered an important aspect of VL epidemiology. Published results suggest that phlebotomine sand flies do not acquire the infection from asymptomatic individuals ${ }^{10}$. Nevertheless, questions regarding the competence of asymptomatic individuals to infect the vector, especially when found in high numbers, remain unsolved ${ }^{11}$.

The present VL control strategies in Brazil are based on the occurrence of symptomatic cases; it is important from a public health perspective, to understand the role of asymptomatic cases in maintaining the infection in urban areas and to identify risk factors leading to disease progression. Unfortunately, the disagreements in the test results observed in the present investigation suggest that the available diagnostic tests are not adequate for identifying asymptomatic infection. Based on the present data, the PCR products submitted to hybridization with specific probes seem to discriminate the real infections and will improve confidence in diagnosing asymptomatic subjects in areas of low prevalence of clinical disease.

\section{ACKNOWLEDGMENTS}

To Secretaria Municipal de Saúde de Sabará, Minas Gerais and Fundação Nacional de Saúde, Minas Gerais, for their cooperation and logistical support. To Dr. Steven Reed (Infectious Disease Research Institute, Seatle) for providing the rk39 antigen and the strip test and Dr. Octávio Fernandes (Fundação Oswaldo Cruz, Rio de Janeiro) for providing the probes for hybridization. To Dr. Vandak Nobre Jr ( Faculdade de Medicina, Universidade Federal de Minas Gerais) for collaboration in clinical exams and Rosangela Fátima Gomes and Roberto Teodoro da Costa for laboratory technical support.

\section{REFERENCES}

1. Andrade ASR, Gomes RF, Fernandes 0, Melo MN. Use of DNA-based diagnostic methods for human leishmaniasis in Minas Gerais, Brazil. Acta Tropica 78:261-267, 2001.

2. Badaró R, Benson D, Eulálio MC, Freire M, Cunha S, Neto EM, PedralSampaio D, Madureira C, Burns JM, Houghton RL, David JR, Reed SG. rk39: A cloned antigen of Leishmania chagasi that predicts active visceral leishmaniais. Journal of Infectious Diseases 173:758-761, 1996.

3. Badaró R, Jones TC, Carvalho EM, Sampaio D, Reed SG, Barral A, Teixeira $\mathrm{R}$, Johnson WD Jr. New perspectives on a subclinical form of visceral leishmaniasis. Journal of Infectious Diseases 154:1003-1011, 1986a.

4. Badaró R, Jones TC, Lorenço R, Cerf J, Sampaio D, Carvalho EM, Rocha H, Teixeira R, Johnson Jr WD. A prospective study of visceral leishmaniasis in an endemic area of Brasil. Journal of Infectious Diseases 154:639-649, $1986 \mathrm{~b}$.

5. Burns JM, Shreffler WG, Benson DR, Ghalib HW, Badaró R, Reed SG. Molecular characterization of a kinesin-related antigen of Leishmania chagasi that detects specific antibody in African and American visceral leishmaniasis. Proceedings of the National Academy of Sciences of the United States of America 90:775-779, 1993.

6. Caldas AJM, Silva, DRC, Pereira CCR, Nunes, PMS, Silva BP, Silva AAM, Barral A, Costa JML. Infecção por Leishmania (Leishmania) chagasi em crianças de uma área endêmica de leishmaniose visceral americana na Ilha de São Luis-MA, Brasil. Revista da Sociedade Brasileira de Medicina Tropical 34:445-451, 2001.

7. Camargo ME, Rebonato C. Cross-reactivity in fluorescence tests for Trypanosoma and Leishmania antibodies. A single inhibition procedure to ensure specific results. The American Journal of Tropical Medicine and Hygiene 18:500-505, 1969.

8. Cançado JR. Long term evaluation of etiological treatment of Chagas disease with Benzanidazole. Revista do Instituto de Medicina Tropical de São Paulo 1:29-37, 2002.

9. Cerf BJ, Jones TC, Badaró R, Sampaio D, Teixeira R, Johnson Jr WD. Malnutrition as a risk factor for severe visceral leishmaniasis. Journal of Infectious Diseases 156:1030-1033, 1987.

10. Costa CH, Gomes RB, Silva MR, Garcez LM, Ramos PK, Santos RS, Shaw JJ, David Jr, Maguire JH. Competence of the human host as a reservoir for Leishmania chagasi. Journal of Infectious Diseases 182:997-1000, 2000.

11. Costa CH, StewartJM, Gomes RBB, Garcez LM, Ramos PK, Bozza M, Satoskar A, Dissanayake S, Santos RS, Silva MR, Shaw JJ, David JR, Maguirre JH. 
Asymptomatic human carriers of Leishmania chagasi. The American Journal of Tropical Medicine and Hygiene 66:334-337, 2002.

12. Costa JM, Durnad R, Deniau M, Rivollet D, Izri M, Houin R, Vidaud M, Bretagne S. PCR Enzyme-linked immunosorbent assay for Diagnosis of Leishmaniasis in human Immunodeficiency Virus-infected Patients. Journal of Clinical Microbiology 34:1831-1833, 1996.

13. Cunha S, Freire, M, Eulálio C, Cristóvão J, Netto E, Johnson Jr WD, Reed SG, Badaró R. Visceral leishmaniasis in a new ecological niche near a major metropolitan area of Brazil. Transactions of the Royal Society of Tropical Medicine and Hygiene 89:155-158, 1995.

14. D’Oliveira Jr A, Costa, SRM, Barbosa AB, Orge MLGO, Carvalho EM. Asymptomatic Leishmania chagasi infection in relatives and neighbors of patients with visceral leishmaniasis. Memórias do Instituto Oswaldo Cruz 92:15-20, 1997.

15. Degrave W, Fernandes O, Campbell D, Bozza M, Lopes UG. Use of molecular probes and PCR for detection and typing of Leishmania-a mini-review. Memórias do Instituto Oswaldo Cruz 89:463-469, 1994.

16. Evans TG, Teixeira MJ, McAuliffe IT, Vasconcelos I, Vasconcelos AW, Sousa AA, Lima JW, Pearson RD. Epidemiology of Visceral Leishmaniasis in Northeast Brazil. Journal of Infectious Diseases 166:1124-1132, 1992.

17. Gama MEA, Costa JML, Gomes CMC, Corbett CEP. Subclinical form of the American Visceral Leishmaniasis. Memórias do Instituto Oswaldo Cruz 99:889-893,2004

18. Jeronimo SMB, Teixeira MJ, Sousa AQ, Thielking P, Pearson RD Evans TG. Natural history of Leishmania (Leishmania) chagasi infection in Northeastern Brazil: Long-term follow-up. Clinical Infectious Disease 30:608-609, 2000.

19. Kwok S, Higuchi R. Avoiding false positives with PCR. Nature 339:237238, 1989.

20. Le Fichoux Y, Quaranta JF, Aufeuvre JP, Lelievre A, Marty P, Suffia I, Rousseau D, Kubar J. Occurrence of Leishmania infantum parasitemia in asymptomatic blood donors living in an area of endemicity in southern France. Journal of Cinical Microbiology 37:1953-1957, 1999.

21. Martin-Sanchez J, Pineda JA, Morillas-Marquez F, Garcia-Garcia JA, Acedo C, Macias J. Detection of Leishmania infantum kinetoplast DNA in peripheral blood from asymptomatic individuals at risk for parenterally transmitted infections: relationship between polymerase chain reaction results and other Leishmania infection markers. American Journal of Tropical Medicine and Hygiene 70:545-548, 2004.

22. Moreno EC, Melo MN, Genaro 0, Lambertucci JR, Serufo JC, Andrade ASR, Antunes CMF, Carneiro M. Risk factors for Leishmania chagasi infection in an urban área of Minas Gerais State. Revista da Sociedade Brasileira de Medicina Tropical 38:456-463, 2005
23. Nuzum E, White Iii F, Thakur R, Dietze R, Wages J, Grogl M, Berman J. Diagnosis of Symptomatic Visceral Leishmaniasis by Use of the Polymerase Chain Reaction on Patient Blood. Journal of Infectious Diseases 171:751-754, 1995.

24. Otero ACS, Silva VO, Luz KG, Palatnik M, Pirmez C, Fernandes 0, Palatinikde-Souza CB. Short report: occurrence of Leishmania donovani DNA in donated blood from seroreactive Brazilian blood donors. The American Journal of Tropical Medicine and Hygiene 62:128-131, 2000.

25. Pampiglione S, Manson-Bahr PEC, Giuingi F, Giunti G, Parenti A, Canestri Trotti G. Studies on Mediterranean leishmaniasis 2 Asymptomatic cases of Visceral leishmaniasis. Transactions of the Royal Society of Tropical Medicine and Hygiene 68:447-453, 1974.

26. Piarroux R, Gambarelli F, Dumon H, Fontes M, Dunan S, Mary C, Toga B, Quilici M. Comparison of PCR with direct examinations of bone marrow aspiration, myeloculture, and serology for diagnosis of visceral leishmaniasis in immunocompromised patiens. Journal of Clinical Microbiology 32:746-749, 1994.

27. Riera C, Fisa R, Udina M, Gállego M, Portus M. Detection of Leishmaniainfantum cryptic infection in asymptomatic blood donors living in an endemic area (Eivissa, Balearic Islands, Spain) by different diagnostic methods. Transactions of the Royal Society of Tropical Medicine and Hygiene 98:102-110, 2004.

28. Sackett DL, Haynes RB, Guyatt GH, Tugwell P. Clinical Epidemiology: a basic science for clinical medicine. Little, Brown and Company, Boston, 1991.

29. Santos FR, Pena SDJ, Epplen JT. Genetic and population study of a Y-linked tetranucleotide repeat DNA polymorphism with a simple non-isotopic technique. Human Genetics 90:655-656, 1993.

30. Shaw JJ, Voller A. The detection of circulating antibody to kala-azar by means of immunofluorescent techniques. Transactions of the Royal Society of Tropical Medicine and Hygiene 58:349-352, 1964.

31. Silva ES, Gontijo CMF, Pacheco RS, Fiuza VOP, Brazil R. Visceral Leishmaniasis in the Metropolitan Region of Belo Horizonte, State of Minas Gerais, Brazil. Memórias do Instituto Oswaldo Cruz 96:285-291, 2001.

32. Silva ES, Gontijo CMF, Pirmez C, Fernandes 0, Brazil RP. Short report: detection of Leishmania DNA by polymerase chain reaction on blood samples from dogs with visceral leishmaniasis. The American Journal of Tropical Medicine and Hygiene 65:896-898, 2001.

33. Sundar S, Reed S, Singh VP, Kumar PCK, Murray HW. Rapid accurate field diagnosis of Indian visceral leishmaniasis. The Lancet 351:563-565, 1998.

34. Vieira JBF, Coelho GE. Leishmaniose Visceral ou Calazar: Aspectos epidemiológicos e de controle. Revista da Sociedade Brasileira de Medicina Tropical 31:85-92, 1998

35. Voller A, BartlettA, Bidwell DE. Enzyme immunoassays for parasitic disease. Transactions of the Royal Society of Tropical Medicine and Hygiene 70:98106, 1976. 